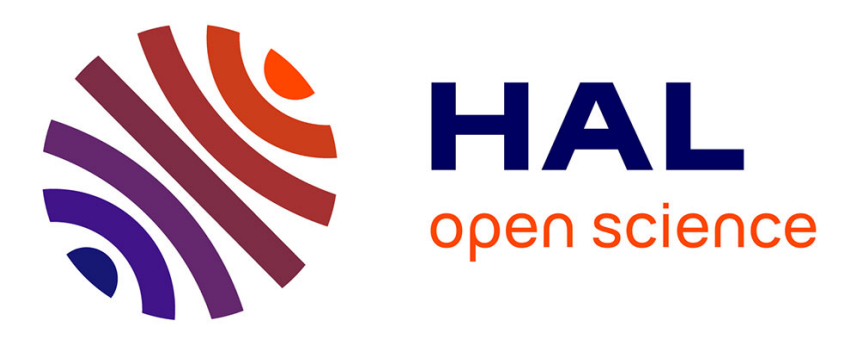

\title{
Dielectric spectroscopy techniques as quality control tool: a feasibility study
}

\author{
Abdelghafour Bouaicha, Issouf Fofana, Masoud Farzaneh, Alireza \\ Setayeshmehr, Hossein Borsi, Ernst Gockenbach, Abderrahmane Beroual, \\ Thomas Aka-Ngnui
}

\section{To cite this version:}

Abdelghafour Bouaicha, Issouf Fofana, Masoud Farzaneh, Alireza Setayeshmehr, Hossein Borsi, et al.. Dielectric spectroscopy techniques as quality control tool: a feasibility study. IEEE Electrical Insulation Magazine, 2009, 25 (1), pp.6-14. hal-00367464

\section{HAL Id: hal-00367464 https://hal.science/hal-00367464}

Submitted on 3 Jun 2009

HAL is a multi-disciplinary open access archive for the deposit and dissemination of scientific research documents, whether they are published or not. The documents may come from teaching and research institutions in France or abroad, or from public or private research centers.
L'archive ouverte pluridisciplinaire HAL, est destinée au dépôt et à la diffusion de documents scientifiques de niveau recherche, publiés ou non, émanant des établissements d'enseignement et de recherche français ou étrangers, des laboratoires publics ou privés. 


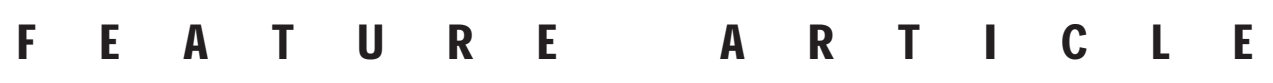

\section{Dielectric Spectroscopy Techniques as Quality Control Tool: A Feasibility Study}

Key Words: Oil-Impregnated Paper (OIP) condenser bushings, dielectric spectroscopy, time domain, frequency domain.

\section{Introduction}

2 ushings are essential elements of many power equipments,

3 including circuit breakers, capacitors, reactors, etc. Both high- and low-voltage windings are insulated from the core and from each other, and leads are brought out through insulating bushings. The two basic bushing designs are non-graded and capacitance-graded. The former is the simplest and the oldest. Capacitance graded bushings are available in four technologies: Resin Bounded paper (RB), Oil-Impregnated Paper (OIP), Resin Impregnated Paper (RIP) and Epoxy Resin Impregnated Paper (ERIP). OIP bushing, developed in the 1920s, is one of the most common types [1]. About $80 \%$ of all bushings in use today are of the OIP type.

Explosive failure often follows bushing deterioration/degradation, frequently resulting in catastrophic and expensive failure of a transformer and heavy damage to adjacent equipment. Accurate monitoring of the condition of bushings in service is therefore of vital importance.

At present, routine maintenance tests most often used for checking the condition of bushings involve visual inspection and power factor/capacitance tests at line frequency [2]. The need to test power system insulation non-destructively and reliably in the field has driven the development of diagnostic tools based on changes in the dielectric properties of the insulation [3]-[14].

In this article, the feasibility of using time- and frequencydomain dielectric spectroscopy measurements to monitor the fabrication of OIP condenser bushings is discussed. Such measurements have been made on a laboratory OIP bushing model. The manufacturing process consisted of three stages, namely fabrication, drying and impregnation. Short-circuit between some of the condenser layers has also been simulated.

\section{Dielectric Spectroscopy Techniques}

The fundamental theories behind dielectric measurements are well known [6], [11], [13]. Dielectric phenomena are discussed in Jonscher's publications [5]. However, to facilitate interpretation of the measurements presented in this paper, a short review

\section{A. Bouaïcha and I. Fofana}

Canada Research Chair, tier 2, Insulating Liquids

and Mixed Dielectrics for Electrotechnology

(ISOLIME), Université du Québec à Chicoutimi,

Chicoutimi, Qc, Canada.

\section{Farzaneh}

International Research Centre on Atmospheric Icing and Power Network Engineering (CenGivre), Université du Québec à Chicoutimi, Chicoutimi, $Q c$, Canada.

\section{A. Setayeshmehr, H. Borsi and E. Gockenbach} Institute of Electric Power Systems, High Voltage Engineering Section (Schering-Institute). Leibniz. Universität Hannover, Hanover, Germany

\section{A. Beroual and Ngnui Thomas Aka}

Ecole Centrale de Lyon, Laboratoire Ampère, Lyon (France).

In this article, the feasibility of using time and frequency domain dielectric spectroscopy techniques to monitor the condition of oil-impregnated paper (OIP) condenser bushings is discussed. 
of the theory behind time and frequency domain measurement techniques follows.

\section{A. Time Domain Spectroscopy}

The measurement of polarization and depolarization currents (PDC) following application of a dc voltage step is one way to investigate slow polarization processes in the time domain [5], [7]-[14]. A dc charging voltage U(t) with the following characteristics is applied to the initially relaxed insulation system:

$$
U(t)= \begin{cases}0 & t \leq 0 \\ U_{C} & 0 \leq t \leq t_{C} \\ 0 & t \geq t_{C}\end{cases}
$$

A long charging time is required (e.g., 10,000 s) in order to assess interfacial polarization and sample condition. During charging, the polarization (or absorption) current $\mathrm{I}_{\mathrm{pol}}(\mathrm{t})$ through the test object is measured. $I_{\text {pol }}(t)$ can be expressed as [4]-[12]:

$$
I_{\mathrm{pol}}(t)=C_{0} U_{c}\left[\frac{\sigma_{o}}{\varepsilon_{o}}+\varepsilon_{\infty} \delta(t)+f(t)\right]
$$

where $\mathrm{C}_{0}$ is the geometrical capacitance of the bushing $=29.4 \mathrm{pF}$, $\mathrm{U}_{\mathrm{c}}$ is the step voltage (charging voltage), $\sigma_{\mathrm{o}}$ is the dc conductivity of the dielectric material, $\varepsilon_{0}=8.852 \times 10^{-12} \mathrm{~F} / \mathrm{m}$ is the vacuum permittivity, $\varepsilon_{\infty}$ is the high frequency component of the permittivity, $\delta(t)$ is the delta function arising from the applied step voltage at $t$ $=0$, and $\mathrm{f}(\mathrm{t})$ is the response function of the dielectric material.

Following the polarization period, the test sample is shortcircuited by removing the applied voltage at $\mathrm{t}=\mathrm{t}_{\mathrm{C}}$, enabling the measurement of the depolarization (or resorption) current $I_{\text {depol }}(t)$ in the opposite direction. $I_{\text {depol }}(t)$ has zero dc conductivity component [13].

According to the superposition principle, the sudden reduction of the voltage $U_{c}$ to zero may be regarded as application of a negative voltage step at time $\mathrm{t}=\mathrm{t}_{\mathrm{c}}$. Neglecting the delta function in (1) we get, for $\mathrm{t}>\mathrm{t}_{\mathrm{C}}[4]-[11]$ :

$$
I_{\text {depol }}(t)=-C_{o} U_{c}\left[f\left(t-t_{C}\right)-f(t)\right]
$$

Figure 1 shows the PDC measuring circuits while Figure 2 shows typical variation of $\mathrm{I}_{\mathrm{pol}}$ and $\mathrm{I}_{\text {depol }}$ following application and removal of the step charging voltage $U_{C}[6]$, [13]. From the PDC measurement currents, the dc conductivity $\sigma_{0}$, can be estimated. If the test object is charged for a sufficiently long time, then $\mathrm{f}\left(\mathrm{t}_{\mathrm{C}}\right)$ $\cong 0$, and the dielectric response function $\mathrm{f}(\mathrm{t})$ will be proportional to the depolarization current. Rewriting (1) as

$$
f\left(t_{1}\right)=\frac{I_{\mathrm{pol}}\left(t_{1}\right)}{C_{0} U_{C}}-\frac{\sigma_{0}}{\varepsilon_{0}}
$$

and (2) as

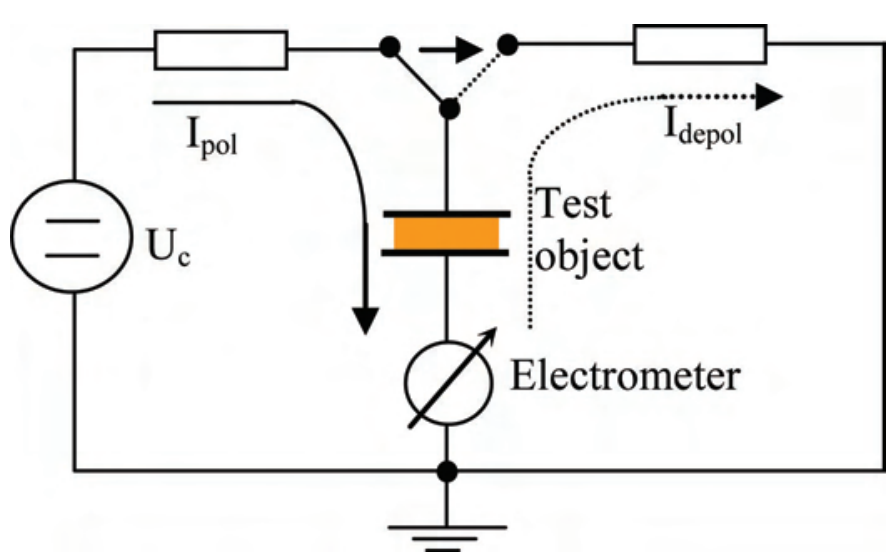

Figure 1. PDC measuring circuitry.

$$
f\left(t-t_{C}\right) \approx \frac{-I_{\mathrm{depol}}\left(t-t_{C}\right)}{C_{0} U_{C}}
$$

we obtain

$$
\sigma_{o} \approx \frac{\varepsilon_{0}}{C_{0} U_{C}}\left(I_{\mathrm{pol}}\left(t_{1}\right)+I_{\mathrm{depol}}\left(t-t_{C}\right)\right)
$$

for any $\mathrm{t}$ and $\mathrm{t}_{1}$ such that $\mathrm{t}_{1}$ (during charging) $=\mathrm{t}-\mathrm{t}_{\mathrm{C}}$ (during discharging) [13], [14].

Even without performing direct conductivity measurements on an oil sample, the oil conductivity can be obtained using (5). In the same way, the conductivity of the paper can be estimated from the long term values of the polarization and depolarization currents.

\section{B. Frequency Domain Spectroscopy}

Instead of studying the polarization in the time domain we can study the dielectric response in the frequency domain when an

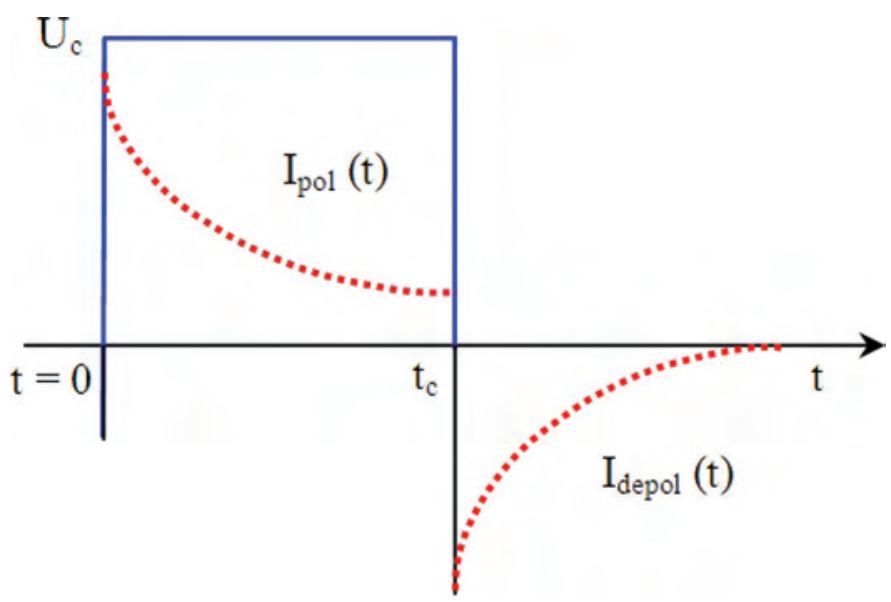

Figure 2. Typical polarization and depolarization currents [6], [13]. 
AC sinusoidal voltage $U(\omega)$ is applied. Fourier transforming the polarization current yields [6], [13]:

$\widehat{I}(\omega)=j \omega C_{o}[\underbrace{\varepsilon_{\infty}+\chi^{\prime}(\omega)}_{\varepsilon^{\prime}(\omega)}-j \underbrace{\left(\frac{\sigma_{o}}{\varepsilon_{o} \omega}+\chi^{\prime \prime}(\omega)\right)}_{\varepsilon^{\prime \prime}(\omega)}] \widehat{U}(\omega)$

where $\chi(\omega)=\chi^{\prime}(\omega)-j \chi^{\prime \prime}(\omega)$ is the Fourier transform of the dielectric response function $\mathrm{f}(\mathrm{t})$, defined as the complex dielectric susceptibility. Given that $\varepsilon(\omega)=\varepsilon^{\prime}(\omega)-\mathrm{j} \varepsilon^{\prime \prime}(\omega)$, the loss factor $\tan \delta$ can be defined as [6]:

$$
\tan \delta(\omega)=\frac{\varepsilon^{\prime \prime}(\omega)}{\varepsilon^{\prime}(\omega)}=\frac{\frac{\sigma_{o}}{\varepsilon_{0} \omega}+\chi^{\prime \prime}(\omega)}{\varepsilon_{\infty}+\chi^{\prime}(\omega)}
$$

Frequency domain spectroscopy (FDS) has been implemented in the Insulation Diagnostic Analyzer IDA 200 [15]. This instrument allows frequency scanning of the capacitance, power factor, dielectric constant and dielectric loss from $0.1 \mathrm{mHz}$ to $1 \mathrm{kHz}$.

\section{OIP bushing design}

A laboratory OIP condenser bushing model has been designed to evaluate the feasibility of using FDS to monitor the fabrication processes (Figure 3). This condenser bushing is essentially a series of concentric capacitors between the center conductor and the ground sleeve or mounting flange. The design offers a capacitively graded, oil impregnated paper condenser bushing. The condenser consists of an electrical grade paper wound over a central conductor. The condenser is fabricated by inserting aluminum foil layers at predetermined locations in order to smooth the field distribution in the bushing. The condenser core is placed inside an insulating envelope of Plexiglas, then heated, vacuum dried, and impregnated with an electrical grade mineral oil.

Cellulose paper used in the OIP laboratory bushing model is a Diamond Pattern Paper (DPP), manufactured by Weidmann [16]

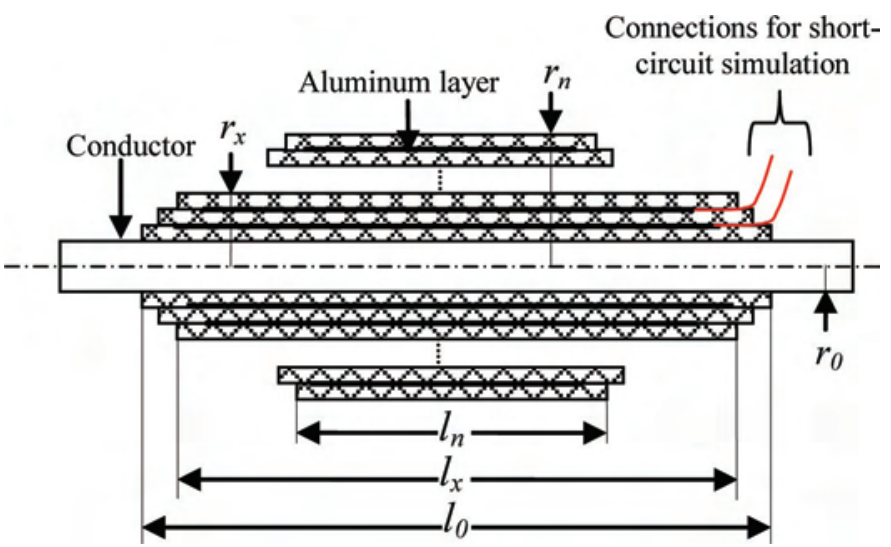

Figure 3. Construction details of a typical condenser bushing rated up to $69 \mathrm{kV}$. with a thickness of $0.125 \mathrm{~mm}$ and a dielectric breakdown voltage of $8.5 \mathrm{kV}$ (measured according to ASTM D-202, Section 143).

Design equations used to manufacture the bushing models can be found in the literature [17], [18]. An overview of the OIP condenser bushing construction is provided in Figure 4.

\section{Experimental Investigations}

In these investigations, polarization and depolarization current (PDC) measurements using a stabilized DC power source up to $2500 \mathrm{~V}$ were analyzed to obtain the dielectric response in the time domain. Analysis in the frequency domain was performed using the IDA 200. Such data are known to be influenced by insulation aging, geometry, moisture content, and operating temperature [6], [7], [10], [13], [19]-[22]. As insulation aging is not part of these investigations, and measurements were made close to room temperature, the most important factors influencing the present data would be voids, moisture, and grading capacitance coupling (short-circuit).

In the present study, the dielectric response was used to investigate the change in the OIP bushing insulation after three steps, namely

1. Immediately after fabrication (machining) of the bushing,

2. after vacuum drying

3. after oil impregnation.

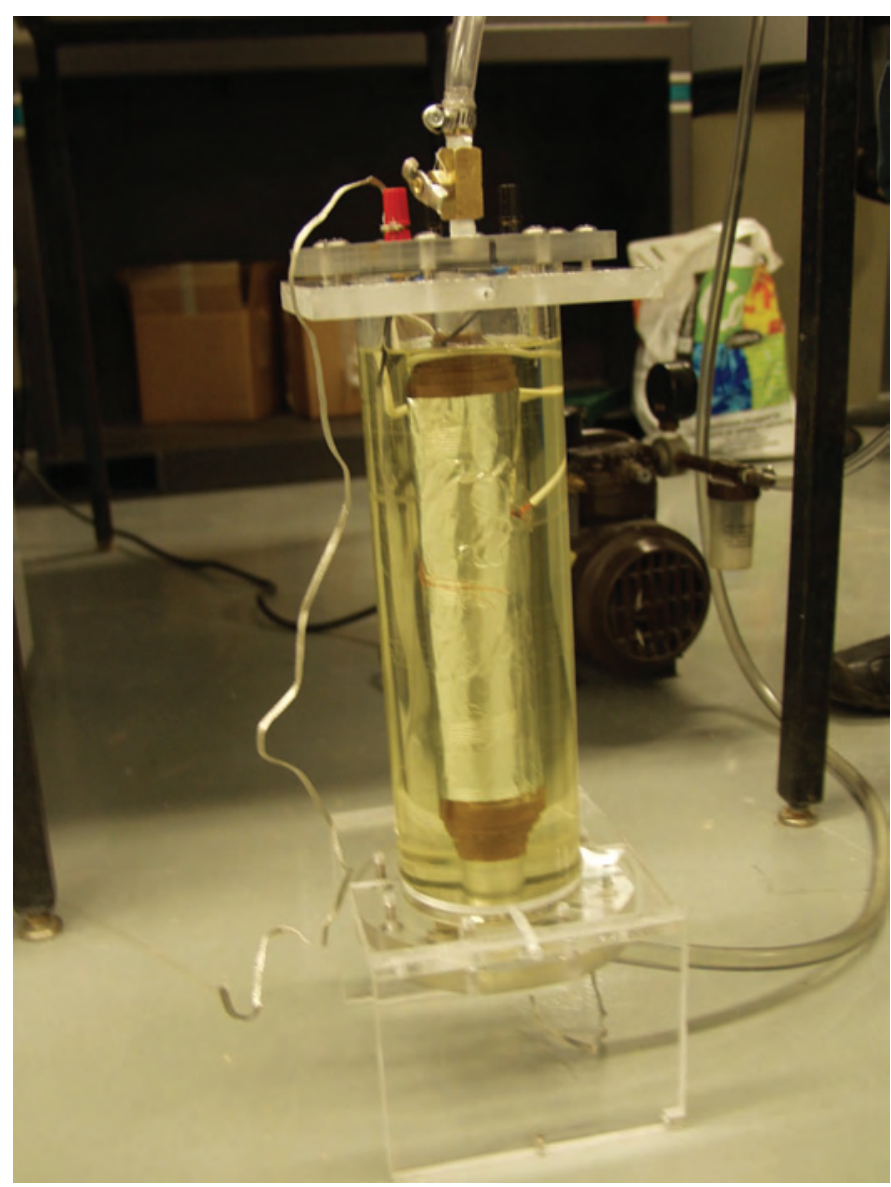

Figure 4. Overview of the OIP condenser bushing. 


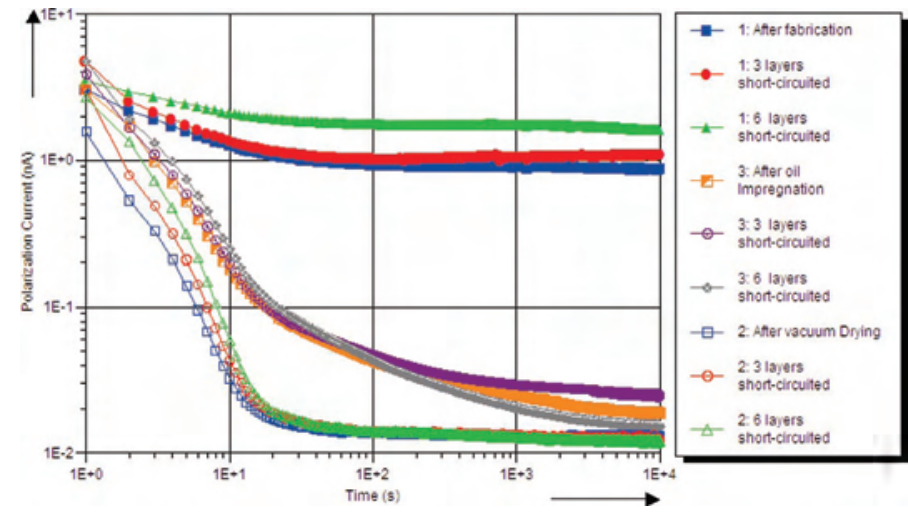

Figure 5. Measured polarization currents for normal and shortcircuited bushing layers following the three processing steps.

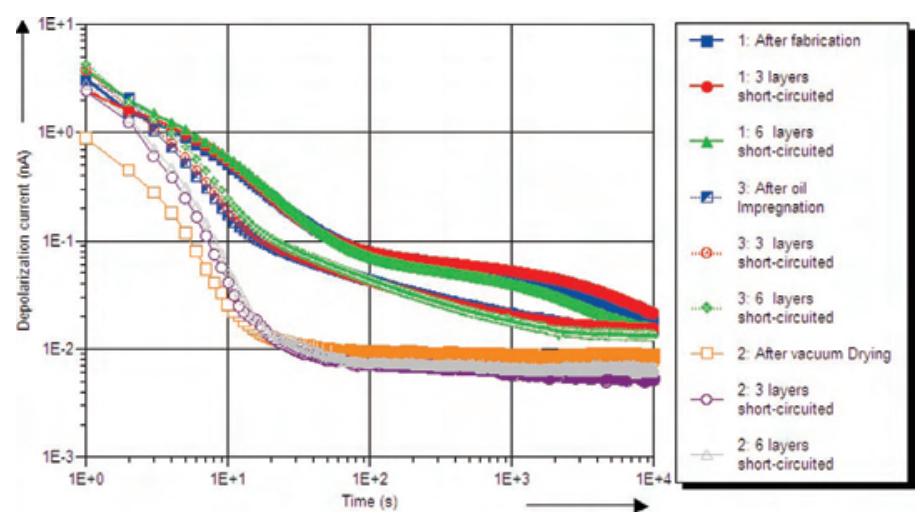

Figure 6. Measured depolarization currents for normal and short-circuited bushing layers following the three processing steps.

The effect of short-circuiting introduced between some of the grading capacitance layers following each step was also investigated. Thus "1:3 layers short-circuited" means that measurements were performed immediately after step 1, with 3 grading capacitance layers short-circuited.

The moisture content of the cellulose paper, as delivered, was measured as $6 \%$ (= the weight of the moisture divided by the weight of the dry, oil-free paper) using a Karl Fisher coulometer. Pumping and heating $\left(<1 \mathrm{mbar}, 105^{\circ} \mathrm{C}\right.$ for $\left.48 \mathrm{hr}\right)$ reduced the water content of the samples to $0.1 \%$. Oil impregnation was then carried out using commercial grade mineral oil which had been purified and vacuum degassed in a two-stage drying unit [23] in order to ensure very low gas (less than $0.5 \%)$ and water $(<5$ ppm) content.

\begin{tabular}{|l|l|l|}
\hline \multicolumn{3}{|c|}{ Table I. Oil and paper conductivity for three different conditions. } \\
\hline & $\sigma_{\text {oil }}(\mathrm{pS} / \mathrm{m})$ & $\sigma_{\text {paper }}(\mathrm{pS} / \mathrm{m})$ \\
\hline 1. After fabrication & - & 1.02 \\
\hline 2. After vacuum drying & - & 0.0052 \\
\hline 3. After impregnation & 0.0942 & 0.005 \\
\hline
\end{tabular}

\section{Results and Discussion}

\section{A. $P D C$}

PDC measurements can provide reliable information about the condition of oil-paper insulation. In this section, the feasibility of using such measurements to monitor the bushing fabrication process is investigated. The user-friendly Labview interface enables the operator to choose the voltage and time for charging and discharging. Polarization and depolarization currents are stored for analysis.

PDC measured at the end of each of the three processing steps are plotted in Figures 5 and 6. It can be seen that the PDC currents measured after drying and impregnation are lower than those measured just after machining.

During the first $20 \mathrm{~s}$ of measurement the PDC currents increase with the number of short-circuited layers. This phenomenon is obviously related to the bushing capacitance. It is clear that further research is needed to understand the specific influence of short-circuited layers on the PDC.

Conductivity values for oil and paper, calculated from the measured PDC using (5), are presented in Table I. The conductivity of paper decreases after the vacuum drying, indicating the removal of moisture from the insulation.

\section{B. Frequency Domain Spectroscopy}

The complex permittivity can be used to characterize the insulation. It is a dimensionless quantity consisting of a real part $\varepsilon^{\prime}$ representing the energy stored in the electric field within the sample, and an imaginary part $\varepsilon^{\prime \prime}$ representing the energy losses. The frequency scans of $\varepsilon^{\prime \prime}$ (Figure 7) demonstrate the possibility of separating the three fabrication steps.

Vacuum drying clearly affects $\varepsilon^{\prime \prime}$. Following oil impregnation, $\varepsilon^{\prime \prime}$ increases, but remains below the values immediately after fabrication. This increase could be due to increased losses at low frequency.

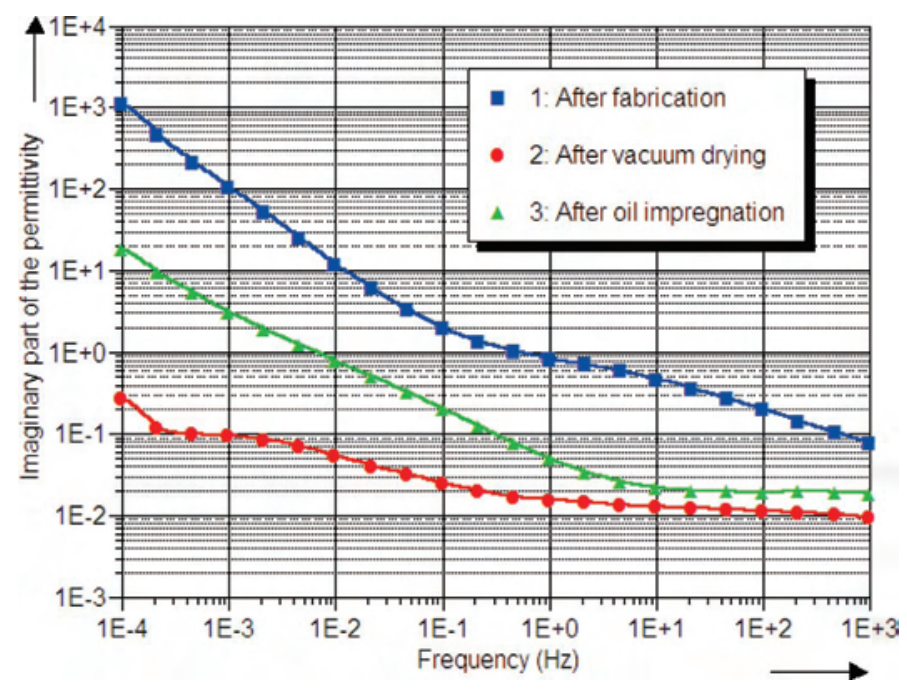

Figure 7. Frequency scan of the imaginary part of the permittivity following the three processing steps. 
Figure 8 shows that short-circuit condition may be detected using $\varepsilon^{\prime}$ measurements in the frequency range below $1 \mathrm{mHz}$. The ac conductivity of the bushings, shown in Figure 9, is remarkably reduced when moisture is removed from the insulating paper.

The dielectric dissipation factor (DDF), also known as the loss factor $(\tan \delta)$, is defined in (7). The power factor (PF), defined as $\sin \delta$, is particularly useful in monitoring the bushing condition [1], [2]. Figure 10 shows the results of PF measurements performed after each of the manufacturing steps. The behavior is similar to that of $\varepsilon^{\prime \prime}$ (Figure 7). After drying and impregnation, the PF drops to values (at power frequency) lower than those obtained just after machining. After impregnation, the PF at higher frequencies is almost the same as after drying, but at lower frequencies it is larger.

The DDF and capacitance (C) values are shown in Figures 11 and 12 respectively. They increase with increasing moisture content, particularly at very low frequencies. This is in agreement with the work of Supatra [12].

The existence of short-circuited sections in the bushing causes an increase in capacitance. To evaluate the feasibility of detecting a short-circuit in the bushing taps, two conditions, namely with and without short-circuiting of some of the layers of two accessible parts of the foils, are considered. The results presented in Figure 12 show that capacitance measurements on bushing taps can be used to detect short-circuit in the layered capacitance. They also highlight the possibility of using FDS techniques to monitor in-service bushings.

The Capacitance Ratio (CR), which is important for machine insulation diagnosis [12], is the ratio between $\mathrm{C}$ at $0.1 \mathrm{mHz}$ and $\mathrm{C}$ at $60 \mathrm{~Hz}$. Lower ratios indicate better insulation quality [12]. Figure 13 shows CR computed from the values of Figure 12. It can be seen that when the moisture content is greater (just after fabrication), the $\mathrm{CR}$ is higher. It decreases after the vacuum drying process and increases slightly after impregnation.

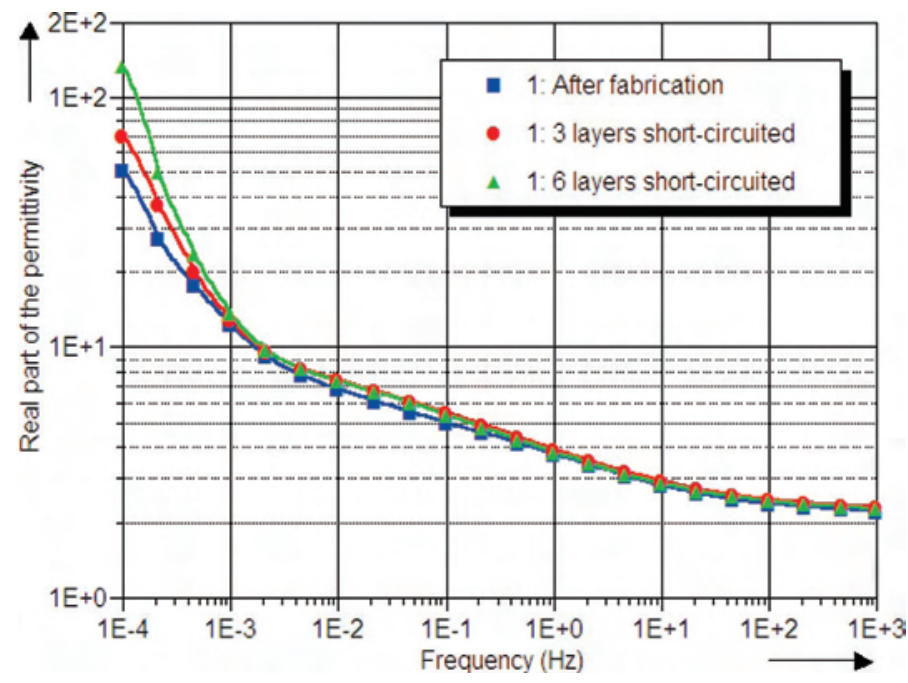

Figure 8. Frequency scan of the real part of the permittivity for normal and short-circuited bushing layers.

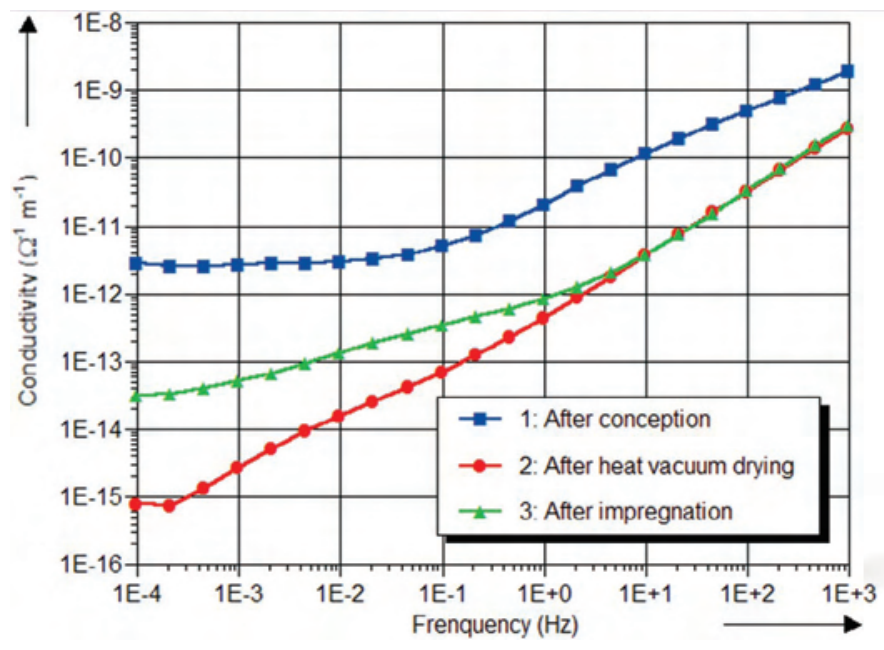

Figure 9. Frequency scan of the conductivity following the three processing steps.

CR seems to be effective in detecting short-circuit just after fabrication. However, after the subsequent steps it is less sensitive to short-circuit. The capacitance itself (Figure 12) is more sensitive.

By measuring the impedance of the bushing model over a wide range of frequencies, the frequency response of the system can be plotted. Figure 14 and 15 show respectively the argument and absolute value of the impedance, $\mathrm{Z}$, of the bushing layers following each processing step. The insulation condition significantly influences both these quantities at frequencies below $0.1 \mathrm{~Hz}$.

\section{Conclusions}

In this article we have described the possible use of dielectric spectroscopy to monitor three steps in the OIP condenser

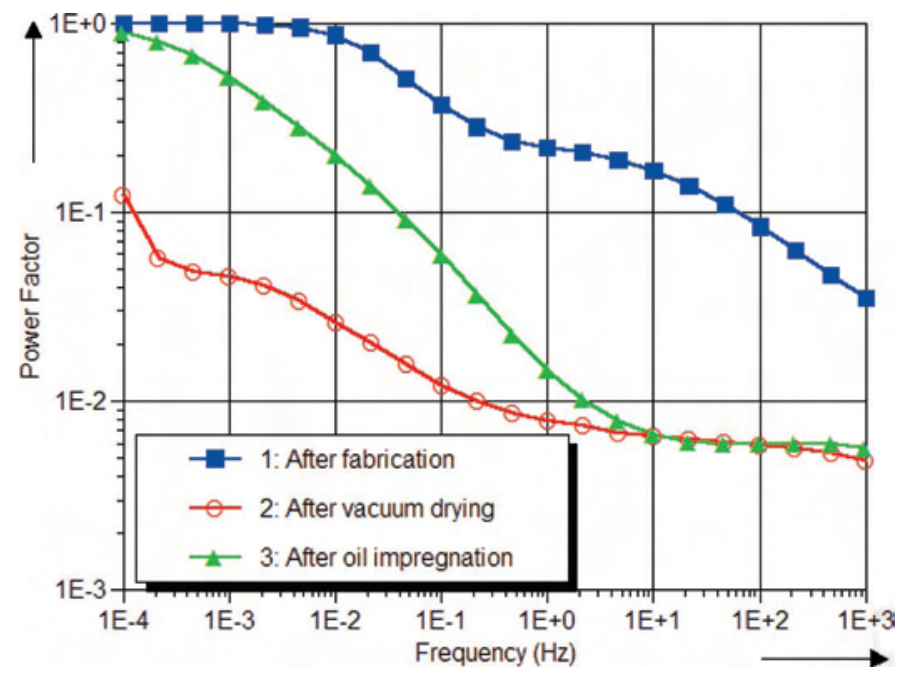

Figure 10. Frequency scan of the power factor following the three processing steps. The moisture content of the oil used for impregnation was 15 ppm. 


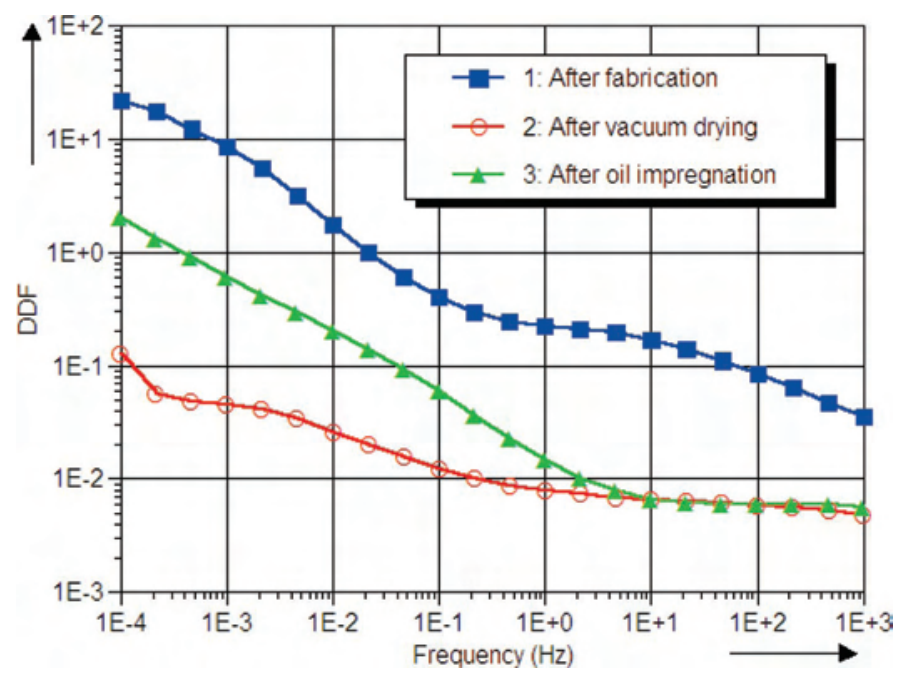

Figure 11. Measured dielectric dissipation factor (DDF) as a function of frequency following the three processing steps.

bushing manufacturing process. These measurements provide a more comprehensive evaluation of the insulation condition than measurements performed only at power frequency.

We have shown that DDF, C, and permittivity measurements on bushing taps at low frequency will detect short-circuiting, as will PDC measurements within $20 \mathrm{~s}$ of application or removal of the poling voltage.

FDS and PDC measurements give a good indication of the insulation condition. These methods are sensitive to moisture content, voids, and short-circuit. The effects of moisture content and short-circuit can also be separated.

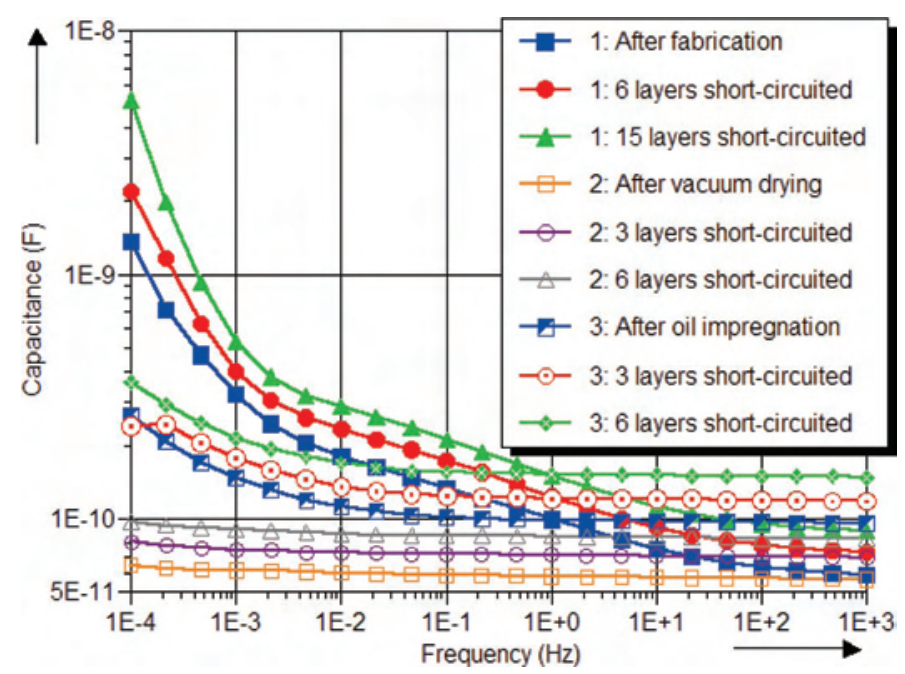

Figure 12. Frequency scans of the capacitance for normal and short-circuited bushing layers following the three processing steps.

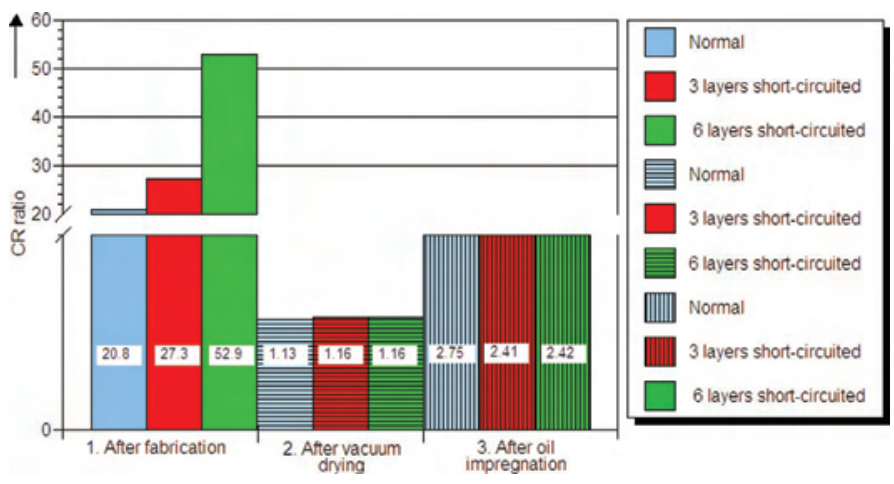

Figure 13. CR computed from values given in Figure 10.

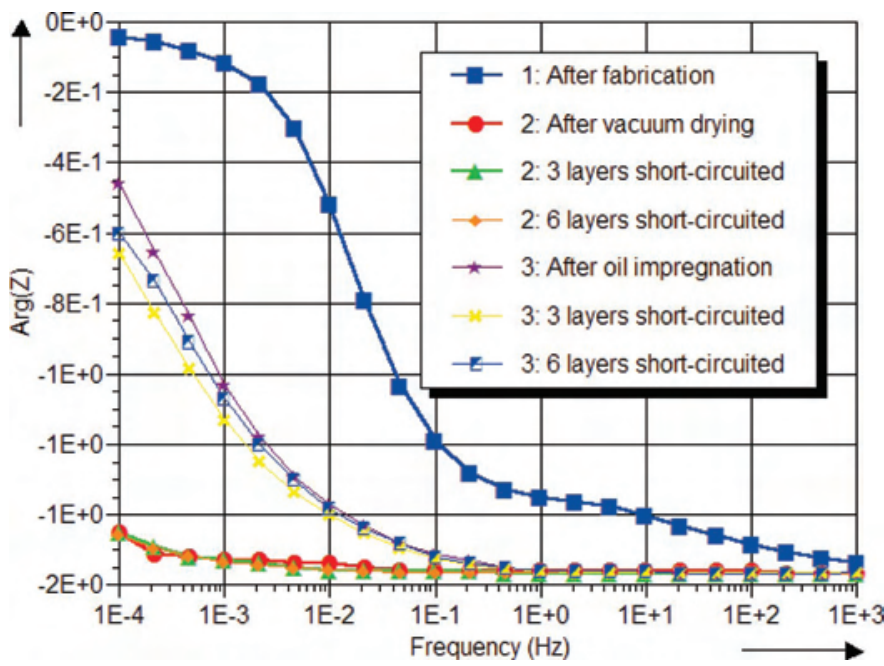

Figure 14. Frequency scans of the argument of the impedance, $Z$, for normal and short-circuited bushing layers following the three processing steps.

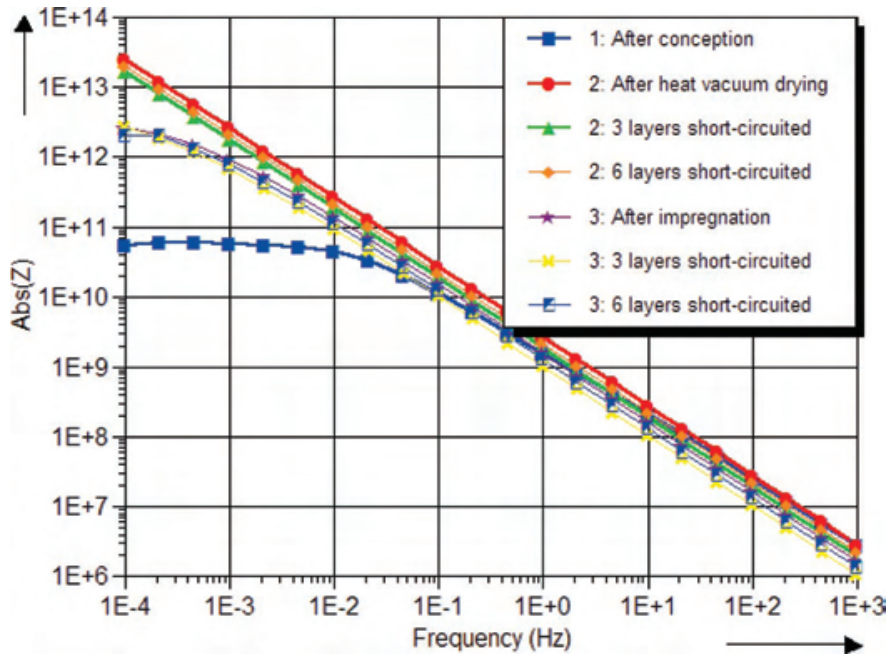

Figure 15. Frequency scan of the absolute value of the impedance, Z, for normal and short-circuited bushing layers following the three processing steps 


\section{Acknowledgments}

This work was carried out within the framework of the Canada Research Chair, ISOLIME, and the International Research Center, CENGIVRE at the University of Quebec in Chicoutimi. The authors would like to thank J. Cross and Weidmann Electrical Technology Inc. (United States) for supplying materials, and all the sponsors of the project. Their thanks are also extended to Mr. D. Tremblay for carrying out some of the measurements.

\section{References}

[1] W. A. Young, "An overview of Lapp insulator high voltage bushing design," Lapp Insulator Company, LeRoy, NY, pp. 1-7. Available online at: http:// www.pcoreelectric.com/downloads/techpapers/techpaper_overview.pdf.

[2] Facilities Engineering Branch Denver Office, "Testing and maintenance of high-voltage bushings," Facilities Instructions, Standards, and Techniques United States Department of the Interior, Bureau of Reclamation, Denver, Colorado, FIST 3-2 11/91, 1991, pp. 1-8.

[3] M. Koch and K. Feser, "Reliability and influences on dielectric methods to evaluate the ageing state of oil-paper insulations," in Proc. 2nd Int. Conf. on Advances in Processing, Testing and Application of Dielectric Materials (APTADM), Wroclaw, Poland, 2004, pp. 95-101.

[4] U. Gafvert, G. Frimpong, and J. Fuhr, "Modeling of dielectric measurements on power transformers," in Proc. 37th CIGRE Session, Paris, France, 1998, paper $15-103$.

[5] A. K. Jonscher, Dielectric Relaxation in Solids. New York: Chelsea Dielectrics, 1984.

[6] A. Seytashmehr, I. Fofana, C. Eichler, A. Akbari, H. Borsi, and E. Gockenbach, "Dielectric spectroscopic measurements on transformer oil-paper insulation under controlled laboratory conditions," IEEE Trans. Dielectr. Electr. Insul., vol. 15, no. 4, pp. 1100-1111, 2008.

[7] T. K. Saha, "Review of modern diagnostic techniques for assessing insulation condition in aged transformers," IEEE Trans. Dielectr. Electr. Insul., vol. 10, no. 5; pp. 903-917, 2003.

[8] S. Okabe, M. Yamada, S. Sato, and E. Mori, "A diagnostic method based on RVM (return voltage measurement) for condenser bushings with oil paper insulation systems," Electr. Eng. Jpn., vol. 130, no. 1, pp. 21-29, 2000.

[9] T. K. Saha and Z. T. Yao, "Experience with return voltage measurements for assessing insulation conditions in service-aged transformers," IEEE Trans. Power Del., vol. 18, no. 1, pp. 128-135, Jan. 2003.

[10] C. D. Paraskevas, P. Vassiliou, and C. T. Dervos, "Temperature dependent dielectric spectroscopy in frequency domain of high-voltage transformer oils compared to physicochemical results," IEEE Trans. Dielectr. Electr. Insul., vol. 13, no. 3, pp. 539-546, 2006.

[10] V. D. Houhanessian, "Measurement and analysis of dielectric response in oil-paper insulation systems," Ph.D. dissertation, Swiss Federal Institute of Technology Zurich, ETHZ, 1998.

[11] A. B. Supatra, "The latest on-site non-destructive technique for insulation analysis of electrical power apparatus," presented at the 2004 Weidmann-ACTI Ann. Tech. Conf., Sacramento, CA, pp. KEA.1-4, 2004, available online at: http://www.weidmann-acti.com/u/library/ bhumiwatpapernov2004.1.pdf.

[12] W. S. Zaengl, "Dielectric spectroscopy in time and frequency domain for HV power equipment, Part I: Theoretical considerations," IEEE Electr. Insul. Mag., vol. 19, no. 5, pp. 5-19 Sep./ Oct. 2003.

[13] W. S. Zaengl, "Application of dielectric spectroscopy in time and frequency domain for HV power equipment," IEEE Electr. Insul. Mag., vol. 19, no. 6, pp. 9-22, Nov./Dec. 2003.

[14] Programma Electric AB, "User's manual for insulation diagnostic system, IDA200," GE Energy Services, Eldarv, Täby, Sweden, 2002.

[15] Weidmann Electrical Technology, "Metric data sheet, diamond pattern data sheet."

[16] L. L. Alston, High Voltage Technology. Harwell Post-Graduate Series. London, UK: Oxford University Press, 1968, pp 228-253.

[17] A. Küchler, Hochspannungstechnik: Grundlagen-Technologie -Anwendungen. Springer-Verlag: Berlin, 2005 (in German).

[18] T. K. Saha and P. Purkait, "Investigations of temperature effects on the dielectric response measurements of transformer oil-paper insulation system," IEEE Trans. Power Del., vol. 23, no. 1, pp. 252-260, 2008.
[19] C. T. Dervos, C. D. Paraskevas, P. D. Skafidas, and N. Stefanou, "Dielectric spectroscopy and gas chromatography methods applied on high-voltage transformer oils," IEEE Trans. Dielectr. Electr. Insul., vol. 13, no. 3, pp. 586-592, 2006.

[20] S. M. Gubanski, P. Boss, G. Csepes, V. D. Houhanessian, J. Filippini, P. Guuinic, U. Gafvert, V. Karius, J. Lapworth, G. Urbani, P. Werelius, and W. S. Zaengl, "Dielectric response methods for diagnostics of power transformers," CIGRE Task Force 15.01, Paris, France, Technical Brochure 254, 2004.

[21] C. Ekanayake, "Diagnosis of moisture in transformer insulation," Ph.D. dissertation, Dept. Materials and Manufacturing Technology, Chalmers University of Technology, Sweden, 2006.

[22] I. Fofana, V. Wasserberg, H. Borsi, E. Gockenbach, and M. Farzaneh, "Drying of transformer insulation using Zeolite," IEEE Electr. Insul. Mag., vol. 20, no. 1, pp. 21-30, Jan./Feb. 2004.

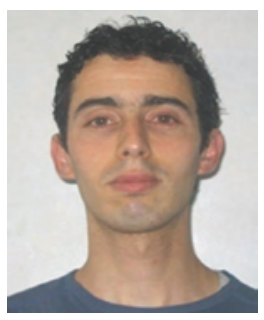

Abdelghafour Bouaicha was born in Algiers, Algeria, in 1981. He received the Diplôme d'Ingnieur en Électrotechnique from the École Nationale Polytechnique of Algiers in 2004, and his Master's degree in 2005 from the École Centrale de Lyon, France. He joined the ISOLIME and CIGELE laboratories at the Université du Québec à Chicoutimi (UQAC) in 2006 where he is currently preparing his $\mathrm{Ph}$.D. thesis. His main research interests include high voltage phenomena, electrical insulation, modeling and computer simulation, and control engineering. $\mathrm{He}$ is author/co-author of six scientific publications.

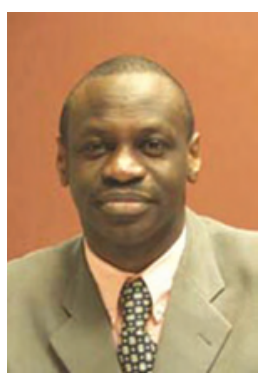

Issouf Fofana (M'05) received an Electro-mechanical Engineering degree in 1991 from the University of Abidjan (Côte d'Ivoire), and the Master's and Ph.D. degrees from the Ecole Centrale de LyonFrance in 1993 and 1996, respectively. During the period November 1997 to August 1999, he held an Alexander von Humboldt Fellowship at the Schering Institute of High Voltage Engineering Techniques, University of Hanover, Germany. He joined the Université du Québec à Chicoutimi (UQAC) as an Associate Researcher in 2000, and is now Associate Professor. Since September 2005, Dr. Fofana has held the Canada Research Chair, tier 2, on Insulating Liquids and Mixed Dielectrics for Electrotechnology (ISOLIME). He is currently a member of the Technical Committee on Energy and Power Systems of the International Association of Science and Technology for Development (IASTED) and also a member of the ASTM Committee D27 on Electrical Insulating Liquids and Gases. He has authored/co-authored more than 100 scientific publications and holds 3 patents. 


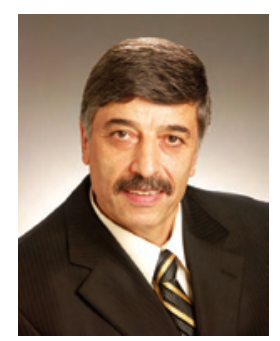

Masoud Farzaneh (M'83-SM'91-F'07) received his electrical engineering degree from the École Polytechnique of Iran in 1973. Subsequently, he received a doctoral degree in engineering from the Institut $\mathrm{Na}$ tionale Polytechnique of the Université Paul Sabatier, in France, and a Doctorat d'État. From 1980 to 1982, he was Associate Professor at Université des Sciences et de la Technologie d'Oran, Algeria. He joined Université du Québec à Chicoutimi (UQAC) in 1982. He currently holds the NSERC/ Hydro-Quebec Industrial Chair on Atmospheric Icing (CIGELE), and the Canada Research Chair on Atmospheric Icing Engineering of Power Networks (INGIVRE). He is the Director and founder of the International Research Centre on Atmospheric Icing and Engineering of Power Networks (CENGIVRE). Prof. Farzaneh is author/co-author of 750 scientific publications on high voltage, outdoor insulation, and atmospheric icing. He is a member of the New York Academy of Sciences and the American Association for the Advancement of Science. He is currently an Associate Editor of IEEE Transactions on Dielectrics and Electrical Insulation, Chairman of the IEEE DEIS Outdoor Insulation Committee, and Convenor of CIGRE Working Group B2.29.

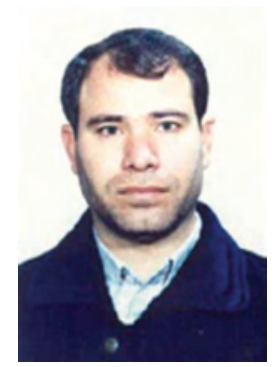

Alireza Setayeshmehr was born in 1969 in Iran. He received the B.Sc. degree from Ferdosi University in 1993, and the M.Sc. degree in electrical engineering from Tarbiat Modarres University in 1996. He was then appointed as a member of the academic staff of Chamran University, Ahvaz, Iran, and since October 2003 has been a Ph.D. student at the Schering Institute of High Voltage Techniques and Engineering at the University of Hannover, Germany. His main research interests are in condition monitoring of high-voltage power transformers.

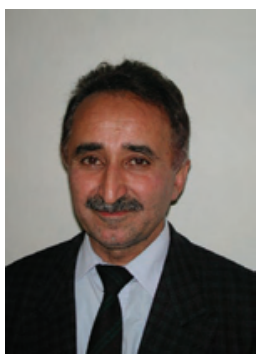

Hossein Borsi received the Dipl.-Ing. degree in electrical engineering in 1972, Dr.-Ing. degree in 1976, and habilitation in 1979 at the University of Hanover, Germany. From 1979 to 1985 , he was Professor of Power Engineering at the University of Mashad, Iran, Dean of the Faculty of Engineering from 1980 to 1982, and scientific adviser to the Ministry of Energy, Iran, from 1981 to 1985 . He is one of the 4 founders of the Reza Transwerke current transformer factory in Iran, and served as its technical director from 1982 to 1985 . Since 1986, he has lectured on high-voltage measuring techniques at the University of Hanover, where he is now Academic Director at the Schering In- stitute. He is a member of VDE and of several CIGRE Task Forces and national Working Groups on standardization. He is author or co-author of more than 250 scientific publications and holds more than 20 patents in the field of high-voltage technology.

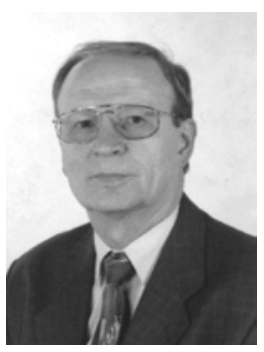

Ernst Gockenbach (M'83-SM'88FM'01) received the Diplom degree in 1974, and the Ph.D. in 1979 from the Technical University of Darmstadt. From 1979 to 1982 he worked at the High Voltage Test Laboratory of the Switchgear Factory Siemens AG, Berlin, and was responsible for the High Voltage Outdoor Test Field. From 1982 to 1990 he was chief engineer for high-voltage test equipment at E. Haefely AG in Basel,

Switzerland. Currently, he is professor of high-voltage engineering and director of the Schering-Institute of High Voltage Technique and Engineering at the University of Hanover. He is a member of VDE and CIGRE, secretary of the CIGRE Study Committee D1 Materials and Emerging Technologies, secretary of the CIGRE Working Group D1-33 High Voltage Test and Measuring Techniques, and a member of national and international Working Groups for Standardization of High Voltage Test and Measuring Procedures.

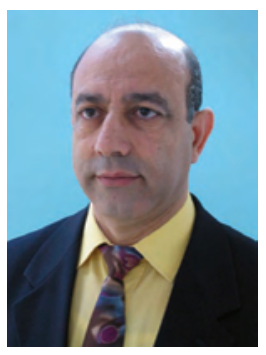

Abderrahmane Beroual (M'92) was born on October 30, 1951. He received the Dipl. Ing. in Electrical Engineering from the Ecole Nationale Polytechnique of Algiers, Algeria in 1976, the Ph.D. from the Technical University of Wroclaw, Poland in 1979, and the Doctorat d'Etat ès Sciences Physiques from the Institut National Polytechnique of Grenoble, France in 1987. In 1980, he joined the Department of Electrical Engineering at the Ecole Nationale Polytechnique of Algiers, and was a researcher at the Laboratoire d Electrostatique et de Matériaux Diélectriques (LEMD)-CNRS of Grenoble, France from 1983 to 1987, and associate professor at the Joseph Fourier University of Grenoble. He was appointed full professor at the Ecole Nationale Polytechnique of Algiers in 1987. In 1989, he joined the Ecole Centrale de Lyon, France where he is presently professor and head of the Dielectric Materials and High Voltage team at the Centre de Génie Electrique de Lyon (CEGELY)-CNRS. His main research interests include high-voltage insulation, lightning, and composite dielectric materials. He is author or co-author of more than 250 papers and holds four patents. He is a member of the International Advisory Committees of the International Conference on Dielectric Liquids and the International Conference on Advances in Processing, Testing and Application of Dielectric Materials. 


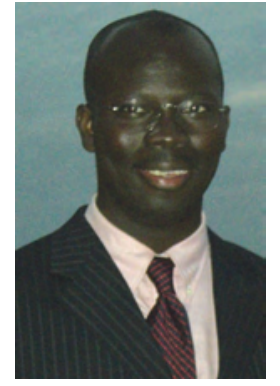

Thomas Aka-Ngnui was born in Abidjan, Côte d'Ivoire, in 1970. He received his physical engineering degree from the Faculty of Science and Technology, University of Abidjan, Côte d'Ivoire, in 1995, and the M.Sc. and Ph.D. degrees from the Ecole Centrale, Lyon, France in 1996 and 2000, respectively. $\mathrm{He}$ is presently an associate professor at the Ecole Centrale de Lyon where he is a member of the Dielectric Materials and High Voltage team at the Centre de Génie Electrique de Lyon (CEGELY)-CNRS. His main research interests include high-voltage phenomena, electrical insulation, dielectric materials, modeling, and computer simulation.

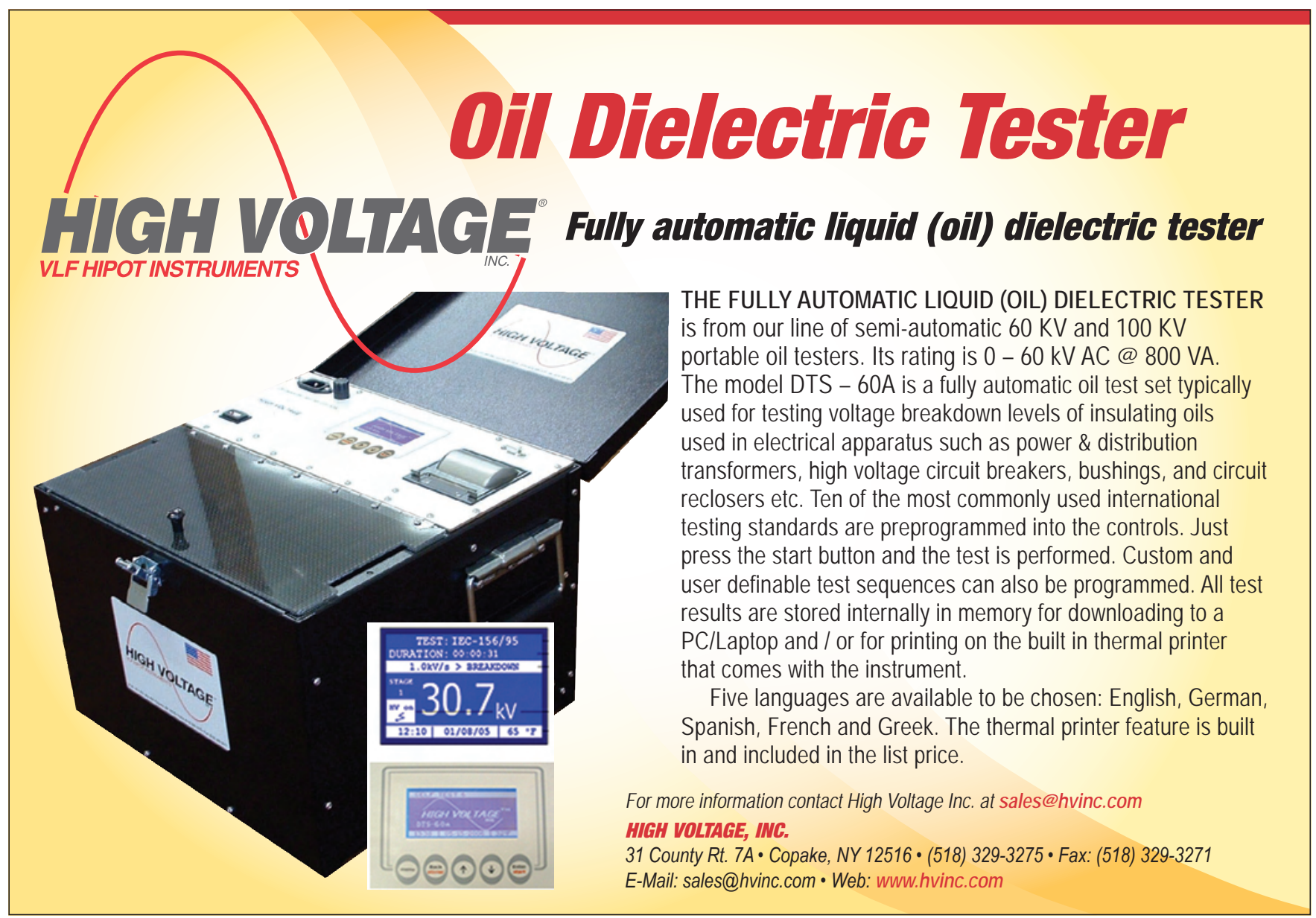

